\title{
REFERENGES
}

LURIA, S. E., AND DELBRÜCK, M. 1943. Mutations of bacteria from virus sensitivity to virus resistance. Genetics, 28, 491-511.

RANK, G. H., AND BEGH-HANSEN, N. T. 1973. Single nuclear gene inherited cross resistance and collateral sensitivity to 17 inhibitors of mitochondrial function in S. cerevisiae. Molec. gen. Genet., 126, 93-102.

VON BORSTEL, R. C., CAIN, K. T., AND STEINBERG, G. M. 1971. Inheritance of spontaneous mutability in yeast. Genetics, 69, 17-27.

VON BORSTEL, R. C., QUAH, S.-K., STEINBERG, C. M., FLURY, F., AND GotTLIEB, D. J. C. 1973. Mutants of yeast with enhanced spontaneous mutation rates. Genetics Supplement, 73, 141-151.

\section{STABILITY OF DIPLOID CLONES OF THE CELLULAR SLIME MOULD DICTYOSTELIUM DISCOIDEUM}

\author{
E. B. GINGOLD* \\ Department of Biochemistry, School of Biological Sciences, University of Leicester, \\ Leicester $L E I$ TRH
}

Received 24.iv.74

\begin{abstract}
Summary
Haploid cultures of Dictyostelium discoideum obtained from the axenic strain $\mathrm{Ax}-2$ were fused with each other and also with the non-axenic strain X9 to produce diploid clones. The diploids were heterozygous for two recessive drug resistance genes and thus by measuring the segregation under nonselective conditions of haploids expressing drug resistance, a measure of the frequency of haploidisation was obtained. It was demonstrated that $\mathrm{X} 9$ when fused with an axenic strain produced diploids of greater stability than those obtained by the fusion of two axenic strains. It has been postulated that X9 carries a gene (or a series of genes) that give rise to diploid stability
\end{abstract}

\section{Introduction}

The cellular slime mould Dictyostelium discoideum has a complex life-cycle (Bonner, 1959). In the presence of a food supply this organism grows as single celled amoebae. Thus when plated on to a bacterial lawn amoebal clones ingest the bacteria and clear plaques in the lawn similar at first in appearance to the plaques formed by phage. On exhaustion of the food supply however the amoebae aggregate and differentiate into spore and stalk cells-these fruiting bodies appearing in the centre of the plaque.

The system has proven to be attractive for studies of cell differentiation (Garrod and Ashworth, 1973). However the development of a useful genetic system has been far behind the cell biological and biochemical studies. By examination of chromosome number (Ross, 1960) and correlation of this with spore size and shape (Sussman and Sussman, 1962) it was shown that $D$. discoideum, although generally found as a haploid, can also exist in a diploid state. However, the nature of the conversions between these states remained obscure until evidence was found for a parasexual

* Present address: Department of Biology, Hatfield Polytechnic, Hatfield, Herts. 33/2-s2 
cycle by Sinha and Ashworth (1969). The existence of the parasexual cycle has since been confirmed both by genetic (Katz and Sussman, 1972) and cytological techniques (Brody and Williams, 1974). Examination of the reassorted haploids obtained from heterozygous diploid clones enabled Katz and Sussman (1972) to demonstrate linkage between a number of genes; more recently mitotic recombination between linked genes in heterozygous diploids has been demonstrated (Gingold and Ashworth, 1974; Williams, Kessin and Newell, 1974). Thus a genetic system useful for the studies on cell differentiation is now available.

An important question remaining unanswered, however, concerns the frequency of the conversion between the diploid and haploid state. There is general agreement that the fusion of two haploid cells to form a diploid occurs at low frequency at the time of aggregation. The stability of these diploids, however, has been the subject of much disagreement. Some authors (Loomis, 1969; Sinha and Ashworth, 1969) have characterised the diploid state as highly unstable and have claimed that diploid clones segregate haploids (or aneuploids) so frequently that tests of dominance cannot be carried out. Others (Katz and Sussman, 1972) have reported stable diploid clones, yielding haploid segregants at frequencies of only $3 \times 10^{-4}$. It was suggested by Brody and Williams (1974) that these differences might result from variations in culture conditions, random variation and methods of reporting results. This report, however, demonstrates that at least some of the variation found is under genetic control.

\section{Materials AND MEthods}

The characteristics and origins of the strains used in this work are listed in table 1. The culture of the organism, media used and the formation of heterozygous diploids by fusion of haploids has been described elsewhere (Gingold and Ashworth, 1974). The diploid clones employed in this work

TABLE 1

Characteristics of strains

\begin{tabular}{|c|c|c|}
\hline Strain & Characteristics & Origin \\
\hline G8 & Axenic, Temperature sensitive & $\begin{array}{l}\text { NMG* mutation of Ax } \\
\text { (Gingold and Ashwor }\end{array}$ \\
\hline G88 & $\begin{array}{l}\text { Axenic, Temperature sensitive } \\
\text { Methanol Resistant }\end{array}$ & $\begin{array}{l}\text { Spontaneous mutant fro } \\
\text { selection on methano }\end{array}$ \\
\hline G24 & Axenic, Temperature sensitive & NMG mutation of $\mathrm{Ax}-2$ \\
\hline G2418 & $\begin{array}{l}\text { Axenic, Temperature sensitive, } \\
\text { Cycloheximide Resistant. }\end{array}$ & $\begin{array}{l}\text { NMG mutation of G24, } \\
\text { cycloheximide. }\end{array}$ \\
\hline $\mathrm{x} 9$ & $\begin{array}{l}\text { Non-axenic, Temperature sensitive, } \\
\text { Cycloheximide resistant, Methanol } \\
\text { resistant, white spores, late } \\
\text { developing brown pigment. }\end{array}$ & Williams, Kessin and $\mathrm{N}$ \\
\hline $\mathrm{H} 10$ & As $\mathrm{X} 9$ & Haploid from $\mathrm{X} 9 \times \mathrm{G} 8$ \\
\hline H18 & As X 9, except no brown pigment & Haploid from $\mathrm{X} 9 \times \mathrm{G} 8$ \\
\hline
\end{tabular}

were all heterozygous for both the methanol and the cycloheximide resistance genes and as these genes are recessive the diploid clones are sensitive to the drugs (Gingold and Ashworth, 1974). Plaques arising from newly formed diploids were cloned so as to eliminate possible parental contamination. 
When the clonal plaques had grown to a size equivalent to 20 generations $\left(10^{6}\right.$ cells $)$ all sporeheads were picked from randomly chosen clones and spores from each clone suspended in sterile water. Each suspension was plated in association with Klebsiella aerogenes, undiluted on to media containing methanol ( 2 per cent $\mathrm{v} / \mathrm{v}$ ) and media containing cycloheximide $(400 \mu \mathrm{g} / \mathrm{ml})$, and diluted on to drug-free media. The frequencies of methanol and cycloheximide resistant cells in the original clone were determined from the number of plaques which appeared on each plate. In some cases the analysis was repeated on sub-clones appearing on the drug-free plates. The results from such further clonings did not differ seriously from those found with the original clones.

The drug resistant sub-clones obtained were tested for their ploidy by examination of spore size (Gingold and Ashworth, 1974). At least 20 and up to 100 resistant sub-clones were tested for each clone and at least three clones analysed from each pair of haploids fused. By this means the frequencies of haploid resistant segregants could be determined. On the assumption that the resistant and sensitive alleles segregate $1: 1$, this frequency is a measure of the total haploidisation.

\section{Results}

Initial experiments were performed with mutants derived from $\mathrm{Ax}-2$, a strain isolated in our laboratory on the basis of its ability to grow on axenic media (Watts and Ashworth, 1970). The instability of the diploids obtained

TABLE 2

Segregation of cycloheximide and methanol resistant progeny by heterozygous diploid clones

\begin{tabular}{|c|c|c|c|c|c|}
\hline \multirow[b]{2}{*}{ Fusion Diploid } & \multirow[b]{2}{*}{$\begin{array}{l}\text { Number of } \\
\text { individual } \\
\text { clones } \\
\text { analysed }\end{array}$} & \multicolumn{2}{|c|}{ Cycloheximide } & \multicolumn{2}{|c|}{ Methanol } \\
\hline & & $\begin{array}{c}\text { Average Frequency } \\
\text { Resistant Progeny } \\
\qquad X 10^{-4}\end{array}$ & $\begin{array}{c}\text { Average } \\
\% \text { Haploid } \\
\text { of Resistant } \\
\text { Progeny }\end{array}$ & $\begin{array}{c}\text { Average Frequency } \\
\text { Resistant Progeny } \\
X 10^{-4}\end{array}$ & $\begin{array}{c}\text { Average } \\
\% \text { Haploid } \\
\text { of Resistant } \\
\text { Progeny }\end{array}$ \\
\hline $\begin{array}{l}\mathrm{X} 9 \times \mathrm{G} 8 \\
\mathrm{X} 9 \times \mathrm{G} 24\end{array}$ & $\begin{array}{r}8 \\
20\end{array}$ & $1 \cdot 0 \pm 0 \cdot 6$ & 50 & $\begin{array}{l}1 \cdot 5 \pm 1 \cdot 0 \\
580+20\end{array}$ & $\begin{array}{c}95 \\
5\end{array}$ \\
\hline G2418 × G88 & 15 & $\begin{array}{l}2 \cdot 6 \pm 2 \cdot 0 \\
62 \pm 45\end{array}$ & 90 & $\begin{array}{r}00 \pm 20 \\
40 \pm 25\end{array}$ & 99 \\
\hline $\mathrm{G} 24 \times \mathrm{H} 10$ & 10 & $1.7 \pm 1.4$ & 55 & {$[49 \pm 40$} & 5] \\
\hline $\mathrm{G} 24 \times \mathrm{H} 18$ & 12 & $2 \cdot 5 \pm 2 \cdot 5$ & 55 & {$[40 \pm 40$} & 5] \\
\hline
\end{tabular}

from fusion of such haploids appeared to be at least an order of magnitude higher than that reported for non-axenic strains (Katz and Sussman, 1972; Williams, personal communication). As a result of the gift of the non-axenic strain X9 by Drs Williams and Newell (Oxford University) it has been possible to compare under standard conditions the stability of diploids with differing genetic backgrounds. The results of this comparison are shown in table 2 .

It can be seen from the table that in most cases a significant proportion of the resistant segregants were diploid. Such diploids result from mitotic recombination and consequently homozygosity of the recessive allele (Gingold and Ashworth, 1974). The appearance of these resistant diploids must be taken into account when using the frequency of resistant plaques to measure the degree of haploidisation. In some cases haploids comprised 
less than 5 per cent of the methanol resistant progeny. Such results are of no use in the estimation of the frequency of haploidisation. Other clones were found to have higher proportions of haploids amongst the resistant progeny. The basis of the variation appears to be genetic, as similar proportions are obtained whenever diploid clones from the fusion of the same strains are tested. Thus, with the exceptions of the above-mentioned methanol resistance results, it is possible to obtain reliable estimates of the percentage of drug resistant haploid segregants from the data in table 2 .

It is clear that X9 gives diploids of greater stability when combined with G8 or G24 than those obtained by the combination of the drug resistant derivatives of these strains, G88 and G2418. When X9 fuses with G8 the frequencies of cycloheximide and methanol resistant haploid segregants can be seen to be around $0.5-1.5 \times 10^{-4}$. A similar figure is obtained for cycloheximide resistant haploid segregants from X9 $\mathrm{G} 24$ diploids. This haploidisation, after 20 generations, is of the order reported by $\mathrm{Katz}$ and Sussman (1972). On the other hand the fusion of G2418 with G88 gave diploids with a frequency of drug resistant segregants between 4 and $6 \times 10^{-3}$. These results are between one and two orders of magnitude apart. They are unlikely to be caused by random variation; in fact no overlap between the results from the individual clones in each of the two classes was found. The simplest explanation for these results would be that X9 carries a dominant gene (or series of genes), not found in the Ax-2 derived strains, which acts to increase the stability of the diploid state.

Additional work is required to characterise and map this gene(s). Two back fusions are shown in table 2 between G24 and the haploids H10 and $\mathrm{Hl} 8$, both isolated from $\mathrm{X} 9 \times \mathrm{G} 8$ diploids. The low frequencies of cycloheximide resistant segregants from these fusions indicate that both $\mathrm{H} 10$ and $\mathrm{H} 18$ carry the stability determinants from X9. It should be noted that these strains are similar to X9 in most other markers and thus it is not unexpected that they carry the stability determinants. Further analysis should indicate any linkages to the known genes.

\section{Discussion}

The results in this paper have demonstrated that differences do exist between the stability of diploids formed from different haploid strains of $D$. discoideum. All strains used in this work initially derive from the same isolate, NC-4 (Raper, 1935). It is tempting to ascribe the alteration in the diploid stability determinants to the large changes on isolation of the axenic strain Ax-2 from NC-4, but this remains speculation. At this stage there is no evidence of any relationship between the axenic and diploid stability characteristics. It should be noted that the strains were all grown in association with bacteria and thus the results cannot be explained on the basis of a difference between stability in axenic and non-axenic growth conditions as postulated by Brody and Williams (1974).

It is important to note that all the diploids examined in this work were of sufficient stability to enable them to be maintained and dominance characteristics determined. In this respect they differ from those described by Sinha and Ashworth (1969) and Loomis (1969). Thus all strains investigated are convenient for further genetic work in that they form diploids stable enough to be characterised while still yielding haploid segregants at 
useful frequencies. The differences between stabilities could be exploited to facilitate one or other of these aspects in particular experiments.

Acknowledgments.-I would like to thank Dr J. M. Ashworth for providing facilities for this work and useful discussion and Mrs Janet Kwasniak and Miss Julie Johnson for technical assistance. The Author was a Beit Memorial Fellow.

\title{
5. ReFERENGes
}

BONnER, J. T. 1959. The Cellular Slime Moulds. Princeton University Press.

BRODY, T., AND WILLIAMS, к. L. 1974. Cytological analysis of the parasexual cycle in Dictyostelium discoideum. 7. Gen. Microbiol. 82, 371-383.

Garrod, D., AND ASHWORTh, J. M. 1973. Development of the cellular slime mould Dictyostelium discoideum. In Microbial Differentiation. Symp. Soc. Gen. Microbiol., 23, 407-435.

GiNGOLD, E. B., AND ASHWORTk, J. M. 1974. Evidence for Mitotic Crossing-over during the parasexual cycle of the cellular slime mould Dictyostelium discoideum. F. Gen. Microbiol. $84,70-78$.

KATZ, E. R., AND sUSSMAN, M. 1972. Parasexual recombination in Dictyostelium discoideum; selection of stable diploid heterozygotes and stable segregants. Proc. Natl. Acad. Sci. U.S., 69, 495-497.

Lоoмis, w. F. 1969. Temperature-sensitive mutants of Dictyostelium discoideum. F. Bacteriol., $99,65-69$.

RAPER, K. 1935. Dictyostelium discoideum, a new species of slime mould from decaying forest leaves. F. Agric. Res., 50. 135-147.

Ross, I. K. 1960. Studies on diploid strains of Dictyostelium discoideum. Amer. F. Bot., 47, 54-59.

SINHA, U., AND AshwORTH, J. M. 1969. Evidence for the existence of elements of a parasexual cycle in the cellular slime mould Dictyostelium discoideum. Proc. Roy. Soc., Series B, $173,531-540$.

sussman, M., AND sussman, R. R. 1962. Ploidal inheritance in Dictyostelium discoideum: Stable haploid, stable diploid and metastable strains. F. Gen. Microbiol., 28, 417-429. WATTS, D. J., AND ASHWORTH, J. M. 1970. Growth of myxamoebae of the cellular slime mould Dictyostelium discoideum in axenic culture. Biochem. F., 119, 171-174.

WILLIAMS, K. L., KESSIN, R. H., AND NEWELL, P. C. 1974. Parasexual genetics in Dictyostelium discoideum: Assignment to linkage groups of genes for acriflavin resistance and growth in axenic medium. F. Gen. Microbiol. 84, 59-69.

\section{CHIASMATA HAVE NO EFFECT ON FERTILITY}

\author{
H. WALLACE \\ Department of Genetics, University of Birmingham, P.O. Box 363, Birmingham B15 2TT, England \\ Received 1.vi.74
}

\section{SUMMARY}

The hypothesis that most gametes are rendered incapable of fertilisation owing to errors of crossing over is examined and found to have no reliable basis. The general high fertility of eggs is sufficient evidence to refute the hypothesis.

\section{INTRODUGTION}

CoHeN (1967-73) has persistently expressed the idea that defects arising from recombination errors during meiosis cause a large proportion of gametes to be incapable of fertilisation. Although this hypothesis could be 